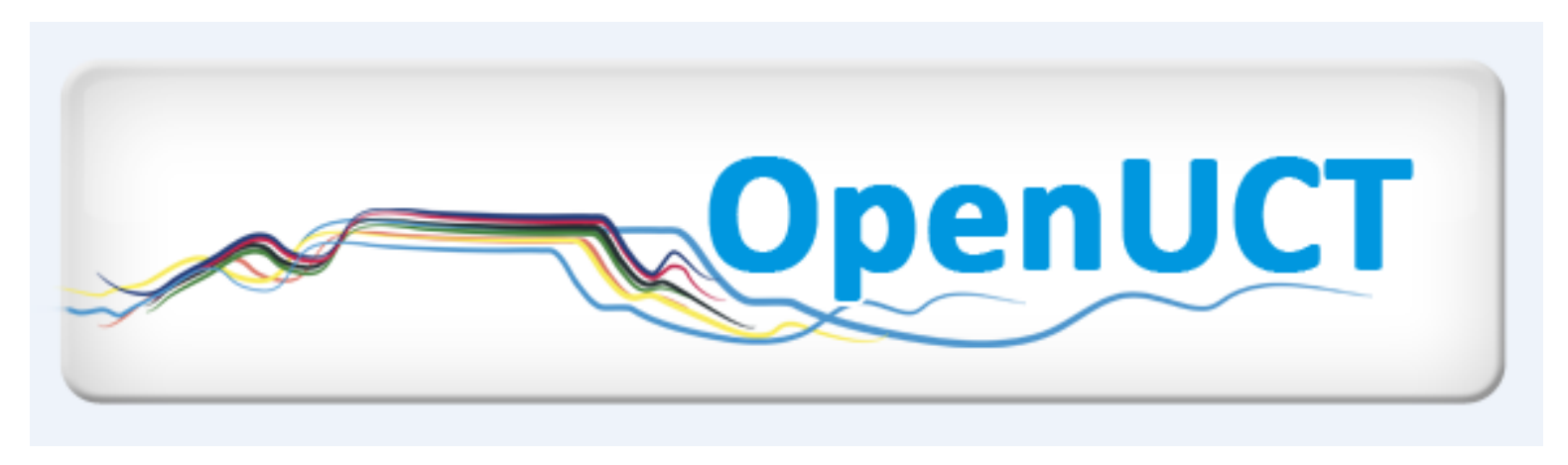

This is the post-print of Carr, T., Morrison, A., Cox, G. \& Deacon, A. 2007. Weathering wikis: net-based learning meets political science in a South African university. Computers and Composition. 24(3): 266-284. DOI: 10.1016/j.compcom.2007.06.001.

It is made available according to the terms of agreement between the author and the journal, and in accordance with UCT's open access policy available: http://www.openuct.uct.ac.za/sites/default/files/UCTOpenAccessPolicy.pdf, for the purposes of research, teaching and private study. 


\title{
Weathering wikis: Net-based learning meets political science in a South African university
}

\author{
Tony Carr ${ }^{\mathrm{a}, *}$, Andrew Morrison ${ }^{\mathrm{b}}$, Glenda Cox ${ }^{\mathrm{a}}$, Andrew Deacon ${ }^{\mathrm{a}}$ \\ ${ }^{a}$ Centre for Educational Technology, University of Cape Town, Cape Town 7701, South Africa \\ ${ }^{b}$ InterMedia, Faculty of Education, University of Oslo, Oslo, Norway
}

\begin{abstract}
Wikis represent flexible tools functioning as open-ended environments for collaboration while also offering process and group writing support. Here we focus on a project to innovate the use of wikis for collaborative writing within student groups in a final-year undergraduate political science course. The primary questions guiding our research were in what ways could wikis assist collaborative learning in an undergraduate course in political science and how we could support educators' in the effective use of wikis? Curiously, wikis may serve as a mediating artifact for collaborative writing even among students who are reluctant to post online drafts. The paper raises questions concerning the nature and limits of lecturer and tutor power to deliver transformative educational innovations in relation to the capacity of students to embrace, comply with, or resist such innovation. In analysing the negotiation of the use of wikis in the course by and among the lecturer, tutors, and students, we draw on two principles in activity theory, which Yrjo Engestrom argued are central to his model of expansive learning: multi-voicedness and contradictions [Engestrom, Yrjo . (1987). Learning by expanding: An activity-theoretical approach to developmental research. Helsinki: Orienta-Konsultit; Engestrom, Yrjo . (2001). Expansive learning at work: Toward an activity theoretical reconceptualization. Journal of Education and Work 14(1), 133-156.]. We add a third principle, transparency, to more fully capture what we observed.
\end{abstract}

Keywords: Wiki; Collaborative learning; Multi-voicedness; Contradiction; Transparency; Mediating artifacts

\section{Introduction}

\subsection{Collaboration and net-based learning}

Collaboration is a central tenet of net-based and technology-enhanced learning (e.g., Lipponen, 2002; Lipponen, Hakkarainen, \& Paavola, 2004). Collaborative project-based work 
is widely used across higher education (e.g., Goodsell, Maher, Tinto, Smith, \& McGregor, 1992, p7; Stahl, 2001). Earlier approaches to collaborative writing on the Web have been extended recently through the ease of use and transparency of writing in wikis. These affordances support flat structures of participation, authoring, and annotation. Wikis are intended to promote texts that are unfolding in their collective processes of meaning making in and across time. What perhaps most distinguishes wikis compositionally are the ways their features can facilitate shared patterns of trust and adaptation in the shaping of collaborative resources. The shared yet emergent character of wikis is apparent in the widely discussed Wikipedia where encyclopedic knowledge is radically reshaped through the practice of multiple and adaptive authorship to build shared meaning (e.g., Bryant, Forte, \& Bruckman, 2005; Giles, 2005).

There is comparatively little research on wikis beyond their more technical aspects (e.g., O'Neill, 2005) despite them being seen as worthwhile additions to the complex of computers and composition programmes and centres (Palmquist, 2003). Educationally, however, wikis may be seen as communicative tools that have the potential to support group interaction, but their uptake depends on the context of their use (Rick \& Guzdial, 2006).

\subsection{Wikis and negotiation}

Wikis pose interesting pedagogical possibilities in undergraduate courses because of the high value placed on critical reflection concerning discipline-specific content. As a product, they serve to share actual disciplinary knowledge. Procedurally, they may also assist in the gathering, appraisal, placement, and distribution of this knowledge. For lecturers, this potential opens up new pedagogical opportunities. It allows for increased meaning making by and between students. Partnership between lecturers and educational technologists with experience in related work and research leads to a collaborative pedagogical design with affordances for negotiation of meaning by students. Together these elements impact on the possible effective uses of a wiki and the resulting dynamic discourses. Yet what seems special about wikis is that they are under-scripted in that they are designed to support flexible (and possibly open ended) collaborative writing projects rather than publication of predetermined knowledge. This characteristic, however, raises questions about the role and place of teachers in the learning process (Lund \& Smørdal, 2006). The most familiar use of wikis is in collaborative projects that need straightforward ways to make identifiable edits to a shared document. Consequently we need to understand how students select and negotiate content and collaborate in meaning making (Andriessen, Baker, \& Suthers, 2003; Baker, Lund, \& Sejourno , 2003; Veerman, 2000, p. 2).

\subsection{Research context and question}

Our research forms part of a wider international collaborative project into how to apply new technologies in building communities of practice (Wenger, McDermott, \& Snyder, 2002) of university educators in the human sciences at a South African university. This research project drew together two centres of net-based learning in a workshop-based approach to building communities of practice for educators. This article presents a situated, course-based collaboration with a political science lecturer who motivates students to articulate their own 
interpretations as part of understanding the changing political landscape of contemporary South Africa and its contested legacies. The primary research questions we asked were in what ways could wikis assist collaborative learning in an undergraduate course in political science and how we could support educators in making effective use of wikis. It seemed that including wikis as part of this course might help support some of its aims and at the same time offer the students, lecturer, and tutors an alternative and additional means of building opportunities for shared meaning making (Wertsch, 1991). Introducing such collaborative tools into a university course presents challenges to students and educators.

\section{Situating and theorizing wikis}

Higher education subject courses have often been innovative in their adoption of educational technologies to encourage the students to engage more deeply with learning activities (Laurillard, 2002). These changes include in approaches to teaching and researching writing (e.g., Palmquist, 2003; Warschauer, 1999). As potentially open-ended environments for collaboration, wikis offer flexible tools for process and group writing. The nature and characteristics of software for writing and the functionalities of online composition environments impact the ways in which teachers, students, and learning designers and researchers may negotiate processes of shared composition. This is especially true where group writing is itself the educational goal and where discussion and critical inquiry are the focus. These goals and principles for fostering dialogue in learning are important for the effective and situated use of wikis.

The use of wikis for teaching in African universities is still highly unusual. We therefore also attempt to show it is possible to work from the experience, critiques, and insights of educators, students, and educational technologists. For us this endeavor has been about weathering change in the uptake and contextualisation of technology-enhanced learning in building a collaborative pedagogy that includes wikis. In an African country that is experiencing and debating significant social and political change, it is the negotiative aspects of including wikis in such a pedagogy of shared meaning making that are of interest.

Stephen Downes (2005) proposed a model of eLearning 2.0 that involves a shift toward student-centred learning in communities of practice. Wikis offer significant affordances for such an approach because web pages can now not only be read but also be easily edited and extended by multiple participants through a browser. The use of wikis opens up a new realm of collaborative sharing and creation of knowledge through learning conversations, where the process is as important as product, the audience is involved in the process, and notions of control over the product may be relinquished by the individual.

The documented uses of wikis in education include process writing, project planning in student teams, sharing of knowledge, online ice breakers, online debate, online discussion, review activities, collaborative writing of documents, and the preparation of ePortfolios (Bruns \& Humphreys, 2005, p. 28; Chen et al., 2005; Guzdial, Jochen, \& Kehoe, 2001). Wikis provide a powerful environment for collaborative process writing because they preserve a record of all steps in a writing process and allow access to material from earlier versions by multiple participants. Susan Garza and Tommy Hern (2006) argued for the importance of wikis "as a tool 
that enables writers to get into the mess and social nature of writing" (n.p.). Miikka Miettinen, Jaaklo Kurhila, Petri Nokelainen, and Henry Tirri (2005) regarded "joint annotation and overall openness and transparency" as attributes of wikis that can support process writing.

There are several educational projects which attempt to share and grow knowledge across a class, such as the MCyclopedia Project (Bruns \& Humphreys, 2005). If students can be persuaded to share early versions of drafts then educators and peers can provide input that enhance the efficiency and effectiveness of the whole writing process. Unfortunately, many students are unwilling to embrace this level of transparency either because sharing early drafts might involve an uncomfortable level of self-exposure or because of fear of plagiarism.

The affordances and design principles propagated from early wikis implicitly conflict with the assessment requirements in most tertiary education systems. Most undergraduate courses allow very short periods for the preparation of products for assessment, and anonymous contributions cannot be assessed. Furthermore, many educators and students have adopted highly instrumental approaches to learning and teaching. Bruns and Humphreys (2005) discussed the challenges to traditional teaching paradigms that are raised at the meeting point of "a conventional education system based on linear production" and "a networked production system" ( $p$. 29). This conflict is most evident where educators try to harness the affordances of wikis to support collaborative writing in a course without changing assessment processes or teaching style.

\section{Wikis as mediating artifacts}

\subsection{Expansive learning}

Our analysis of the use of wikis is underpinned by a socio-cultural approach to learning that originates with Lev Vygotsky $(1962,1978)$. In this approach, meaning making by participants in a situated learning process is of primary concern (Engestr" m, 2001; Lave \& Wenger, 1991; Wertsch, 1991). A socio-cultural perspective allows us to address relationships that develop in the collaborative use and shared meaning making with information communication technologies such as the wiki. For Yrj” Engestr" m, learning is in flux (1987); it weaves and wanders in a process of realisation and change. This dynamic quality applies to the people and the institutional formations within which and between which they function. It also applies to their relations to mediating artifacts, in this case the wiki. In this sense, the wiki becomes both a tool for choice and action and a flexible and extensible environment for collaborative negotiation of meaning. Following Marx Wartovsky (1979) a wiki is a tertiary artifact that "feeds back into actual praxis, as a representation of possibilities which go beyond present actualities" ( $p$. 209).

In a socio-cultural frame, meaning making may be seen as activity centred, drawing together participants' shared understandings in relation to the context of their learning and their own appropriation (Wertsch, 1991). The structure of an activity includes needs, motives, goals, actions, and operations (Leont'ev, 1978, 1981). Activity theory researchers are grappling with developing conceptual tools to address matters of multiple mediations, perspectives and voices, and increasingly the intersection of different tools in shared activities. Collectively produced and mediated artifacts - from tools to cultural signs and communication — are seen as multi- 
mediated. Here attention is also being given to how multiple mediations may be understood horizontally as much as vertically (Leont'ev, 1978, 1981).

The multiple mediations characteristic of wikis also point to their potential for transformation. The model of "expansive learning" developed by Engestrom (1987) described the major categories in the stages of transformation. These are pertinent to the use of wikis as mediating artifacts, as students will go through these in collaboratively producing a piece of writing. Engestrom $(1987,2001)$ argued that we can identify five main principles as central to expansive learning: (1) the activity system as the unit of analysis, (2) multi-voicedness, (3) historicity, (4) contradictions, and (5) expansive transformations. In analysing the negotiation of wikis in the course by the lecturer, tutors, and students, we focus on two of these features: multi-voicedness and contradictions. To this we add a third, transparency.

\subsection{Multi-voicedness}

Multi-voicedness refers much to the inheritance of the dialogical from Mikail Bakhtin (e.g., 1981). Bakhtin conceived of utterances as having embedded in them the address such that every utterance stands in relation to others. Shared understanding is arrived at through negotiation that takes place between participants in dialogical processes realised through intersecting activity (Wells, 1999). This negotiation now includes the uses of digital tools in collaborative learning (e.g., Rasmussen, Krange, \& Ludvigsen, 2005). Voice is important in the various levels of the activity system in articulating perspectives on and between mediating artifacts/tools, the subject, rules, community, or division of labour. Geared toward an object (that may itself shift in this inter-related system), the outcome may also be directed toward intersecting with another activity system with the result being a potentially shared object. In this process, the dialogical character of meaning making is important. In terms of wikis, the multiple participants and discourse threads need to be seen as integral to shared meaning making in a process that involves both peer and educator mediation.

\subsection{Contradictions}

Contradictions emerge in the playing out of activity systems and are realised at different levels (Engestr" m, 1990; Kuutti, 1996). When there is a core or primary activity, contradictions may emerge from within it. At a secondary level, we may witness tensions arising between the components of a system. At a third level, contradictions may arise between current and more advanced motives of the central activity and their distinctions and cultural development. Finally, there is a fourth level of contradiction that may occur between the central activity and those that are proximal and related. In these dynamics of activity systems, the object of the activity too may shift so that, for example, a mediating artifact as an instrument-producing activity may become the object of a subsequent activity. The relationships between changes in linked activity systems are core to the analysis in this article.

\subsection{Transparency}

Transparency is a prerequisite for multi-voicedness and renders contradictions visible. In a socio-cultural approach to meaning making it is how learners negotiate these dynamics in rela- 
tion to new tools and environments that is interesting (e.g., Jahreie \& Ludvigsen, 2005). It is a challenge to consider when and how learners explicitly or implicitly identify transitions, breakdowns, and contradictions in their own group collaboration. Learning inside and with a new tool set may well accentuate the nature of students' own learning practices in ways they have not necessarily articulated themselves. We suggest that the use of a wiki for collaborative writing can provide the transparency of process required to support the negotiation of meaning in shaping an emerging text. This transparency of group process also challenges well-established models of teaching and learning and may provoke uncertainties and anxieties for both educators and students. Facing these emerging experiences, different students may respond very differently, at the same time, within the group and in conjunction with other members in the group. Just how collaboration is effected and shared at a wider level, then, also becomes a matter for concern and study.

\section{The course design}

\subsection{Background, aims, and wiki}

The political science lecturer in this study has a broad educational focus that extends beyond discipline-specific skills to include generic graduate skills and learning experiences about diversity in South Africa. Her other innovations over several decades have included service learning, collaborative work, and process writing. An earlier version of the course included online class debates and group writing exercises in discussion forums. This proved to be challenging because of limited physical access to computers, inefficiencies in student groups, and reluctance by many students to adopt new modes of discourse.

The research site was a third-year undergraduate politics module with 174 students that aimed to "demonstrate the connections between theories and empirical science and suggest the way in which we can firstly, understand how the past shapes the present and secondly, identify the emergence of new political, economic, and social processes" (Department of Political Studies, 2005, p. 2). The module was taught through whole class lectures and in tutorial groups of 15-20 students each. The site for the intervention was a sixweek series of lectures and tutorials to introduce critical engagement with "the theories, arguments, and concepts most commonly employed in the discussion on the historical and contemporary context of the third world" (Department of Political Studies, 2005, p. 2).

The collaborative writing exercise using the wiki lasted 4 weeks in total and culminated in the production of individually composed essays and collaboratively written introductions and conclusions by student teams. The use of the wiki for collaborative process writing (Figure 1) was a pilot intervention with an almost symbolic assessment incentive, which also meant that students who chose to make limited use of the environment would not be severely penalized. The students had access to wikis for three weeks before submitting their assignments. Groups that shared at least intermediate drafts of their individual essays could gain an advantage in the writing of the introduction and conclusion. 


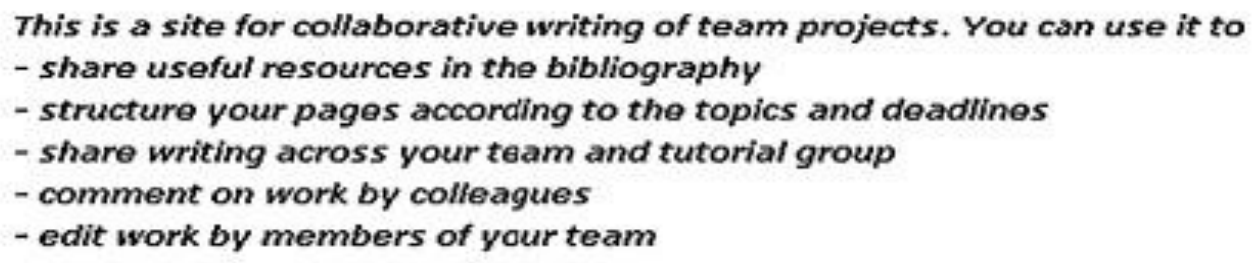

Fig. 1. Extract from the wiki opening page explaining the purpose of using a wiki.

\subsection{Group work}

Students worked in teams of 4-6 within their larger tutorial groups. The students were assigned to teams chosen by their tutors to ensure diversity within each group. Each group considered one aspect of the political development of a country assigned to their tutorial group. Each student took responsibility for one aspect of this topic. In a group writing on the politics of identity, one student might write about the politics of religious identity, and another might write about the politics of gender identity; however, the whole team was responsible for a collaboratively written introduction and conclusion. The wiki was introduced in a lecture during the first week before the teams had been formed and then again in 45-minute lab sessions in the second week when students and tutors could start working together in groups. One wiki was used for each tutorial group. Engagement with the wikis was scaffolded by the use of a template for group pages that students could use for the specifics of their small group projects.

\section{Understanding participants' experience of wikis}

\subsection{Method and sources of information}

The desired outcomes of the collaborative writing activity could only be achieved if students were able to use their wikis as spaces for the negotiation of shared meaning rather than resisting the introduction of a process that challenged their accustomed modes of writing. The nature of educator action is also vital to the success or failure of this intervention. We are able to use several forms of quantitative and qualitative data to analyse the extent and nature of student and educator use of wikis.

Two quantitative data sets were gathered. These were server logs and student evaluations of the use of the wiki. The server logs allow for some quantitative measure of participation across the class by 174 students in the form of page edits and comments posted. Some 55 student evaluations were completed; these provide some insight concerning students' experience in group writing using a wiki.

The qualitative data collected include detailed descriptions of the collaborative design of the wiki and the observations and presence of one researcher who supported the use of the wiki in the course. We have also drawn on notes and reflections on meetings and reviews with the lecturer. Semi-structured interviews were conducted with 7 students, 2 tutors, and the lecturer. All versions of the texts in the wikis were stored on the server, including comments and page edits. To gain deeper insight concerning student writing strategies offline, we would 
have needed to gather and analyse handwritten drafts, word documents, emails, and audio recordings of group conversations.

The log files provide information about the long tail of participation that is typical of online interaction where most participants are responsible for a very small number of logins and messages. Extracts from the comments and the history of wiki pages provide some clues concerning the patterns of use, including integration into the workflow of individuals and groups. Some triangulating evidence is available from the evaluation survey and from student and educator interviews. Student participation exists in a complex relationship to educator action, so these can be considered in tandem.

\subsection{Varied use}

The $\log$ files indicate that the wikis were used very unevenly across the class of 174 students. For example, 26 students (15\% of the class) made no page edits at all, and 97 students (56\%) made no comments. The 44 students $(25 \%)$ who were each responsible for more than 20 page edits accounted in total for over $64 \%$ of all page edits across the class. Similarly, the 48 students $(28 \%)$ who each made two or more comments accounted for just over $92 \%$ of the total comments in the wikis. Of the 55 students who completed the evaluation forms, $91 \%$ were first-time users of wikis, but only $14 \%$ of the respondents mentioned difficulty using the wiki. Student comments ranged from "very user friendly and easy to access" to a statement that "it was difficult to figure out where to write the essay." One comment referred to the difficulty of "working with non-cooperative group members" in a wiki. Only $70 \%$ used the wiki in the last week before the deadline, $33 \%$ used the wiki to review each other's work, and $24 \%$ of respondents reported that comments in the wiki informed improvements in their work.

\subsection{Nature of student comments}

Students were encouraged to comment on writing by other team members. In the most active groups, students used comments to arrange meetings, negotiate logistics, share references, and provide encouragement to peers. Figure 2 illustrates how a student offered encouragement to their team members and suggested what issues they still needed to take into account. The dominant discourse in this extract is both informal and emotive. It highlights the importance of emotional engagement by students with a learning process.

\footnotetext{
You guys (State) $i$ changed my topic to the role of the state in implementing anti-corruption drives, which is a big issue in China currently!II Everyone elses work looks superb!II Thumbs up peoplellI To that dude who $\mathrm{i}$ met at the Library photocopying facilities today, who's also doing the same subgroup (STATE), diff tutorial -- i don't care for anything NEGATIVE you have to say about my topic, because all you're doing is describing the nature of the state,etclll if the reader wanted to know this information -GOOGLE, hello? Its not quite sufficient in merely describing the nature of the state and political form, therefore my subgroup (props to you guys!!!) has set out to deal with more than that and dealt with more compelling issues and implications for the State of China! Corruption is big in Contemporary China! Take this as some good advice not a bunch of criticisms, that you fed me, which i appreciated, but was, how do they say it in laypersons' terms? USELESS!!! So there! :) lol
}

Fig. 2. Student comment on group contents page. 


\subsection{Nature of student edits}

The timing of student edits and the nature of these edits are transparent from the history that is saved for each page. Most students practiced page edits in the Sandbox page during the lab sessions. From the student interviews and wiki logs it was clear that most students only returned to editing pages in their wikis in the final week before the assignment deadline. Typically this involved substantial edits involving copying and pasting of text documents developed outside the wiki. Often there was only one recorded edit operation when the student copied and pasted the final draft of their individual work into their wiki page to demonstrate a superficial compliance with the use of the wiki. We compare two page histories to demonstrate two very different student strategies in the use of the wiki.

Student 1 made seven page edits during one week. Most of these appear to have been entered by copy-and-paste from text entered in Word. There were five major extensions and edits of the page including a formal bibliography. One of the smaller changes involved a change of page title. This history implies the student used the wiki as an environment and tool to facilitate their own process writing.

Student 2 made a few larger edits, mostly within one day. After an initial posting of a short plan, the student posted three further edits two days later between 4 a.m. and 12 p.m. Blocks of text were copied and pasted into the wiki. The last edit replaced deleted paragraphs with a new version of the same paragraphs. This student was clearly engaged with the use of the wiki but mostly used it to facilitate the rapidly staged just-in-time production of their individual essay.

These two strategies had serious implications for the student groups. The first strategy facilitated the writing of the collaborative introduction and conclusion by making drafts of individual work available to the group members several days before the deadline. The second strategy hindered the collaborative writing of an introduction and conclusion because peers could not consult early drafts.

\section{Multiple reflections}

\subsection{The lecturer}

The political science lecturer believed in the importance of teaching values and communication skills required for social development and personal success in the new South Africa as well as discipline-specific and generic graduate skills. She wanted students to work in diverse groups to "learn to communicate across cultural barriers."

She saw wikis as collaborative spaces that would allow for more effective educator intervention into the writing process. She was able to access the wikis in the evening and identify "argument flaws." Her approach then was to suggest where students could improve their writing or to "get into an intellectual discussion." She believed that the "tutors who used it like that really made a difference to the students." She suggested that some of the student resistance to change was related to anger "about an institution that doesn't give them those writing skills." She understood there was a combined "reluctance to share and a 
holding back." Some students perceived sharing early drafts in their wiki as "too exposing." On the other hand, one of her top students was reluctant to offer review comments to peers.

The lecturer reflected that tutors must be trained to "provide the cascade where they empower the student to be able to make comments on their own work and other people's work." She reported that students who took ownership of the wiki "were really excited about the process." She remarked that these students "let go of their work" and noted the unusual phenomenon of "essays ready before completion date." Students who were unwilling to share drafts in their wikis came to her "to get the same kind of assistance." She concluded that "they felt safer coming and doing it person to person."

\subsection{Students}

Collaborative learning interventions raise perceived risk levels for students. Every student can seemingly tell stories of collaborative activities that failed because a group member did not deliver an agreed contribution. Kenneth Chapman and Stuart Van Auken (2001) identified that students did not like team assignments because of compromised grades, unfair workloads, conflicts, and heavier time commitments. They found that student attitudes toward group work were more positive when instructors discussed group management techniques and group dynamics with them. Perhaps students who are able to optimize the group process may perceive the transparency of a wiki as a vital part of the group's information system. Student team effectiveness is also affected by team cohesion (DeeterSchmelz, Kennedy, \& Ramsey, 2002), which depends on common goals and personality differences. Such cohesion is undermined by both free riders and the "lone wolf" who prefer to work on their own in the belief that they can be more successful without the team (Bacon, Stewart, \& Stewart-Belle, 1998; Feldman Barr, Dixon, \& Gassenheimer, 2005). Some students respond to free riders by making an extra effort while others find their motivation and interest decreases (Huff \& Jones, 2002). Educators who wish to change the micro-activity systems of a course through the introduction of collaborative writing using new tools have to factor student fears and skepticism about group learning into their strategy.

Seven students were interviewed shortly after completing the collaborative writing project. Generally they reported limited confidence in the ability of their peers to deliver agreed outcomes in the group project. They had limited initial knowledge of their groups because members were chosen by the tutors. One student remarked "You don't know their level of grammar or English grasp," suggesting that reluctance to edit weak writing by a peer may impact group dynamics.

Some students described tensions within their groups resulting from personality differences, a lack of common goals, and limited commitment to collaboration by some group members who were "just not interested." One student reflected that "its' hard when you have been working alone for three years and then all of a sudden people want you to work together." Two student interviewees fit the lone wolf profile (see Feldman Barr et al., 2005). It seems that resistance was directed at teamwork and that if group members were committed to working well together they would do so both face-to-face and online. 
The need to work online presented a possible technological barrier to group work. In the student evaluation survey, only $14 \%$ of the students said the wiki was difficult to use. All the students in the interview reported ease of use; however, physical access surfaced as a theme. Two students suggested that participation by other members of their groups was limited because they only had access to computers in labs on campus. Another student made very good use of the wiki from the computer labs.

The evaluations (45\%) and some of the interviews imply that many students were reluctant to post early versions of their work. Some preferred to write essays at the last minute while others expressed fears concerning how peers or educators would respond to rough early versions. Two students were concerned about the risk of plagiarism by their peers. One student simply preferred working face-to-face and thought many of his classmates shared this preference. We are also aware that many students may feel safer preparing handwritten or word-processed drafts.

In a very active group, members were online almost every day. One student interviewee was happy to post early versions of her work for review and found that comments made by teammates helped her improve her essay. She reported that the experience had been very useful and that she wanted all her courses to have a collaborative learning environment.

Student reluctance to use the wikis sometimes represented resistance to working collaboratively; however, the lecturer suggested that the intervention resulted in increased engagement with the writing process. Several students engaged in collaborative process writing without posting drafts to the wikis. Students who were reluctant to share early drafts of their writing online arranged face-to-face consultation with the lecturer or met with peers during tutorials. For students who used the wiki as a collaborative writing environment, it was convenient to go online at times that suited them rather than arranging extra face-to-face meetings.

Students adopted a range of strategies in response to this intervention. A small minority made no use of their wikis while another group of students used them only for compliance purposes to demonstrate an advanced or final draft online. These students were able to limit the transparency of the collaborative writing process to their educators and often also to their peers. A significant minority of students grappled with learning to use the wiki in tandem with face-to-face meetings. Only a small minority were unequivocally positive about the use of the wiki in the context of their own learning curves and the sometimes-fraught dynamics of their groups. These students were able to use the contradiction between the collaborative writing project and dominant models of teaching and learning as an opportunity to develop their voices as writers in the discipline and their teamwork skills.

\subsection{Tutors}

Tutors play a crucial role in a massified university education system with a diverse student population. Massification and cost pressures have driven changes in teaching systems over several decades, including the pervasive employment of postgraduate or even senior undergraduate students as tutors instead of senior academics. Many of these issues are captured by divisions of labour in our activity systems. 
The early challenges tutors experienced concerned assessment. Before the intervention, tutors expressed anxiety about the impact on the workload and complexity of assessment. The resulting compromise was that the tutors would take account of student online participation in the marking of the final assignment. Only $5 \%$ of the total mark for the assignment would be allocated to use of the wiki. The ambivalence of one tutor was manifest in a statement to students that the students would not be marked on their uses of the wikis. In retrospect, the design of our intervention took insufficient account of the difficulties in supporting effective tutoring. By week three, it seemed there was a strong correlation between the level of tutor feedback and encouragement and the level of student use of the wikis.

The first author interviewed two tutors. We were interested in identifying successful strategies adopted by tutors and their roles in influencing student participation. Both tutors were aware of the difficulty of working in student teams and the insecurity that may be experienced by group members. They referred to negative experiences of group writing in their own undergraduate years. Tutor 1 was concerned that students would not receive feedback from peers or would "just do their own thing separately and just download it onto the wiki so everyone could see." She highlighted the common student practice of producing work just before deadline as inimical to group process writing. Tutor 2 referred to the crucial role of group dynamics. He stated that "people really don't like group work. There were a lot of personality clashes." He also noted that many students were not motivated to "get involved and do a lot of work."

Tutor 1 was somewhat cynical about the way students might either avoid the use of the wiki or just post work online at the deadline. She stated that as a result "even if there were contributions they wouldn't really change much." Tutor 2 described a clear awareness of how the transparency of the wiki could support collaborative process writing. He stated that "everything is logged or listed on a Wiki so that you know how much each person is doing and I think it is actually a more on-hand group work assignment." This meant that he could "check as a tutor what exactly they were doing and make suggestions." He also saw that use of the wikis could help to avoid face-to-face group tensions and to ease the logistics of collaboration with a group.

Tutor 1 was unclear about her role that she initially described as that of facilitator and then later in the interview as supportive. She gave students time to discuss their essays during tutorials. She posted messages online to prompt students to post in the wiki but did not comment online on the content of what they submitted. Tutor 2 characterised himself as an advisor but also someone who was supportive. He would sometimes remind students online to participate and also "raise it in class." This latter strategy, he felt, encouraged students to use the wiki and see the benefits. He also allocated tutorial time for student group meetings.

Tutor 1 was acutely aware of group dynamics but did not remember discussing ways of getting around the obvious "tensions" with students. Tutor 2 attempted to diffuse group tension through discussions in class or within a specific groups. He advised groups on allocating clear tasks to ensure a fair division of labour. His advice to students included that they "be quite honest in addressing these types of issues, but get [the] whole group to. . . commit to things" and "make sure that each person's tasks are quite clear and typed out in the final project."

Tutor 1's two groups exhibited lower-than-average use of their wikis. In the first group, 8 students (out of 20) did not participate, and in the other group 7 did not make any postings or comments. However, 12 students made over 10 page edits and 9 of these 12 made over 
20 page edits. All but 4 of Tutor 2's students across both of his groups used their wiki and 20 of his students made over 20 page edits. He reported that when students "were actually writing, it was of some assistance." Tutor 2's students were able to make more effective use of their wiki. This can be attributed to the consistent encouragement and engagement and his overt interventions concerning group process and workflow. For Tutor 2, the wiki was a site of negotiation and anticipation of student needs. These findings could suggest that the active presence of the educator as process and writing consultant is required to transform an intervention from disquieting contradiction to an opportunity for creative action by students. Students also may be more likely to risk the transparency of the wiki if their educators show that they value student voices through a writing process.

\subsection{Contradictions in relation to changing practices}

The introduction of a wiki for collaborative writing represented a disruptive change in activity systems. Students, tutors, and the lecturer all experienced contradictions within the micro-activity system of the course and through its interactions with interlinked and macrolevel activity systems at faculty and university levels. These included imbalances between returns, efforts and value created, the need to learn or develop a new domain, shifts in practices of teaching and learning, and dealing with discomfort and limited participation.

Students experienced a perceived imbalance between mark allocation as reward for shortterm performance and the effort and risk of failure required to gain these rewards. Students were also likely to be focused on the imperative of completing their degrees and gaining employment or admission to postgraduate study. For the educators, the related imbalance was between additional preparation and teaching time and the value of their work in terms of student learning. This was most manifest in the uncertainties of tutors concerning the assessment process. For the lecturer there was a potential question concerning the additional time she commits to teaching outside the formal classroom in a research university that provides limited incentive for teaching innovation. Fortunately, the educators and most students were also motivated by factors beyond short-term returns.

This intervention was crucially about shifting practices. For the students it was the shift of practices from just-in-time individual projects to a process of collaborative writing in the wiki. For the tutors and lecturer, it was the shift of practices needed to facilitate collaborative writing in the wiki that would allow greater access to the writing processes of students. The lecturer was able to provide committed leadership and role modeling throughout the intervention. Unfortunately, engagement by many students and even some tutors was constrained by a combination of the limited incentives for participation and their own fears.

Finally, all actors had to confront issues of discomfort with change. Students were dealing with both their own anxieties and with the discomfort and limited cooperation of peers who were unfamiliar with the new collaborative and discursive practices. Several students who were also in a final-year economics course with an exciting experiential and collaborative pedagogy may have felt better equipped to deal with the changes. The tutors and lecturer needed to deal with student unease and resistance evoked by the reshaping of the micro-level activity system. The lecturer had weathered far more severe expressions of student resistance to change; however, some of the tutors were less familiar with this terrain. 


\section{Conclusions}

\subsection{Wikis and collaborative learning}

We have explored how learning designs involving wikis might assist collaborative learning in a traditional undergraduate module in political science that depends predominantly on face-toface lectures and tutorials for its formal teaching and learning. We were particularly interested in how the transparency of the wiki could reveal underlying contradictions in the activity systems involving the course as well as the constraints, divisions of labour, and rules that impact on the emerging design and facilitation of computer-supported collaborative process writing.

By their final undergraduate year, student actions demonstrated they understood an initially mysterious institutional activity system and knew both what was required of them and how to sustain its delivery. Fears concerning changes in the activity system were focused primarily on the lecturer's attempt to change the rules of the system and only secondarily (and mostly symptomatically) on the change in toolset. If students see themselves as productive agents within an activity system, then significant change within the system would be disruptive and undermine their efficiency in the short term. Ambivalence and resistance by tutors has a similar motivation.

The students were generally under-prepared for this kind of work and were accustomed to working at their own pace. This work ethic, for the majority, meant concentrating their effort immediately before the due date. Such a mode of working has implications for the design of future interventions using wikis in a longer and hopefully more durable process. The value in using wikis is likely only to be recognized when several group-writing tasks form a part of their undergraduate degrees. Tutors also need to be encouraged to openly discuss group tensions and help students work out timelines of work and the allocation of tasks. A self-motivated tutor succeeded in doing this with one group, but we need all tutors to use a similar strategy, which would require a greater focus on the specialised training of tutors in both the use of wikis and the strategies for teaching with wikis.

An interesting inference from the survey and interviews is that sharing early drafts of writing feels dangerously self-exposing to a significant proportion of students. Thus, the changes in the activity system were initially seen by many students as personally threatening. One implication is that first-year university courses are a more appropriate site for introducing reshaped activity systems. Another implication may be the need for a longer intervention to provide opportunities for students to experience more of the benefits of change relative to the initial disruption.

\subsection{Wikis and intersecting activity systems}

Wikis are a tool in the form of both a software application and a powerful set of affordances for collaborative writing within appropriate learning design and activity systems. Changes in the activity systems of a single course need to be considered in relation to changes in the activity systems at the level of the whole university and society. There is pressure to transform the South African university education system to ensure it is both representative and supportive of the broader society and reaches outward internationally while continuing to offer a high quality 
education that prepares students for the workplace. In our study, the politics lecturer chose to use wikis as part of a broader response to diversity, student numbers, perceived poor academic literacies, and the need to develop social and graduate skills in her course community.

\subsection{On transparency}

The transparency, openness (Miettinen et al., 2005), and ease of use of wikis constitute powerful affordances for collaborative process writing. At the simplest level, transparency of the writing process allows for timely intervention by educators and peers to ensure that students receive useful feedback and guidance at early and intermediate stages in the process. At a deeper level, this transparency reveals endemic challenges in facilitating collaborative process writing that are not unique to online interventions. These challenges may include a lack of trust by students in the team members and the group process and a reluctance to share early drafts of writing with even a small group of peers. The role of tutors in facilitating such processes is vital. At a more fundamental level, the interaction within, around, and about the use of the wiki is a politicized engagement with attempts by educational innovators to change both micro- and macro-level activity systems in higher education. The uneven use of wikis as social spaces where students could share and comment on drafts also suggests the need for an improved understanding of the tools that students use and need in working collaboratively.

\subsection{Negotiation}

Activities such as the use of wikis in computer-supported collaborative writing are designed to empower students through a process of knowledge sharing and shared meaning making. Such interventions, however, evoke a wide range of responses as students attempt to negotiate an unfamiliar and potentially risky terrain. The introduction of new goals, processes, and tools changes the implicit contracts between lecturers, administrators, and students and confronts students with the uncertainties and limited trust (Huff \& Jones, 2002) of technologised group work and the insecurity of sharing early drafts of their work. Educators also need to negotiate this new collaborative terrain amid their own uncertainties about managing student processes and challenges to accustomed assessment processes. Consequently some educators may be reluctant to use collaborative designs in their teaching while others may provide ambivalent support for group processes. Both educators and students need to tolerate discomfort to negotiate within the risk zone created by such an online collaborative intervention if they are to find ways forward (Augar, Raitman, \& Zhou, 2004).

This intervention adapted the "open ended discursive processes" typical of the original wikis developed by Ward Cunningham (2006) and exemplified most recently by Wikipedia to support production of assessable artifacts with known authors. The symbolic mark allocation for use of the wiki provided students with at most a nominal penalty for making limited use of the wiki. This factor simultaneously limited online participation by students with an instrumental motivation and also defused overt resistance to the process. The encouragement by the lecturer and tutors to use the wiki for collaborative writing in addition to responses by educators to 
drafts in the wiki also served to facilitate student engagement with collaborative writing at a more generic level. This included group meetings in tutorials and groups and individual consultation with the lecturer.

Contradiction is an inevitable part of system change in activity theory (Engestrom, 1999). These changes are not always unidirectional or progressive. Depending on their perceived interests, actors may choose to resist change. Contradictions may provide opportunities for expansive learning, but they may also be experienced and manifest as obstacles to learning. Introducing wikis in collaborative learning raises questions about the negotiation of the nature and limits of lecturer and tutor power in delivering transformative educational innovations. Negotiation of shared meaning within wikis is contingent on the capacity of students to embrace, comply with, or resist innovation as part of the wider and ongoing negotiation that is at the heart of the transformation processes in higher education.

\section{Acknowledgements}

The Information and Communication Technologies in University Communities of Teaching (ICT-UCT) Project, that gave rise to our staff development project and our research into teaching with wikis was funded by the Research Council of Norway and the National Research Foundation in South Africa from 2004 to 2006. Thanks are due to the educators at UCT who have shared their perspectives on teaching with a wiki and to the students who shared their experiences of writing in a wiki. Special appreciation is due to a dedicated political science lecturer who stepped into the risk zone by teaching with a wiki for the first time. We also want to thank colleagues in the Centre for Higher Education Development at the University of Cape Town and in InterMedia at the University of Oslo who have supported our research with generative questions, advice, and encouragement.

Tony Carr is the staff development coordinator at the Centre for Educational Technology at the University of Cape Town (<http://www.cet.uct.ac.za $>$ ). His research and practice are mostly about the role of communities of practice in developing educator and institutional capacity to teach with technology. Other interests include online facilitation, online and mixed mode collaborative learning, and the educational use of wikis and blogs.

\footnotetext{
Andrew Morrison is based at InterMedia, an interdisciplinary research centre at the University of Norway. His current research spans projects in mixed reality arts, mobile collective narrative, genre in digital media, and the mediation of research online. His forthcoming publications include an edited collection Inside Multimodal Composition (Hampton Press, forthcoming) and chapters in Exploring Digital Design (Springer, forthcoming). He was the Norwegian project leader for the ICT-UCT project that supported this research.
} 
Glenda Cox is a staff development officer at the Centre for Educational Technology at the University of Cape Town, South Africa. Initially, her focus was on the use of qualitative research software and content analysis tools to analyse synchronous and asynchronous online conversations in university courses. Since 2003, her work has been focused on researching the take-up and effect of staff-development initiatives. She also works in a mentoring role with academics who have attended workshops and started new technology interventions.

Andrew Deacon is a learning designer in the Centre for Educational Technology at the University of Cape Town, South Africa. His work involves engaging with academics in staff-development initiatives and curriculum projects to collaboratively create ICT-based learning activities. His research interests have focused on the designs and development of learning activities and learning environments.

\section{References}

Andriessen, Jerry, Baker, Michael, \& Suthers, Dan. (2003). Arguing to learn: Confronting cognitions in computersupported collaborative learning environments. Springer.

Augar, Naomi, Raitman, Ruth, \& Zhou, Wanlei. (2004). Teaching and learning online with wikis. In R. Atkinson, C. McBeath, D. Jonas-Dwyer \& R. Phillips (Eds.), Beyond the comfort zone: Proceedings of the 21st ASCILITE conference. Perth, Western Australia, 5-8 December: ASCILITE. Available: $<$ http://www.ascilite.org.au/conferences/perth04/procs/contents.html>.

Bacon, Donald, Stewart, Kim, \& Stewart-Belle, Sue. (1998). Exploring predictors of student team project performance. Journal of Marketing Education, 20(1), 63-71.

Baker, Michael, Lund, Kristine, \& S' journ', Arnauld. (2003). Computer-supported collaborative learning in the space of debate. In B. Wasson, S. Ludvigsen, \& U. Hoppe (Eds.), Designing for change in networked learning environments: Proceedings of the international conference on computer support for collaborative learning 2003 (pp. 11-20). Dordrecht: Kluwer Academic Publishers.

Bakhtin, Mikail. (1981). Discourse in the novel. In Michael Holquist (Ed.), C. Emerson \& M. Holquist (transl.). The dialogic imagination: Four essays by M.M. Bakhtin (pp. 259-422). Austin: University of Texas Press.

Bruns, Axel, \& Humphreys, Sal. (2005). Wikis in teaching and assessment: The M/Cyclopedia Project. WikiSym '05, October 16-18, San Diego, California, USA.

Bryant, Susan L., Forte, Andrea, \& Bruckman, Amy. (2005). Becoming Wikipedian: Transformation of participation in a collaborative online encyclopedia. Group '05, November 6-9, Sanibel Island, Florida, USA.

Chapman, Kenneth J., \& Van Auken, Stuart. (2001). Creating positive group project experiences: An examination of the role of the instructor on students' perceptions of group projects. Journal of Marketing Education, 23(2), $117-127$.

Chen, Helen L., Cannon, David, Gabrio, Jonathan, Leifer, Larry, Toye, George, \& Bailey, Tori. (2005). Using Wikis and weblogs to support reflective learning in an introductory engineering design course. In American Society for Engineering Education Annual Conference\& Exposition. American Society for Engineering Education.

Cunningham, Ward. (2006). Wiki design principles. Retrieved November 7, 2006, from <http://c2.com/cgi/ wiki?WikiDesignPrinciples>.

Deeter-Schmelz, Dawn, Kennedy, Karen, \& Ramsey, Rosemary. (2002). Enriching our understanding of student team effectiveness. Journal of Marketing Education, 24(2), 114-124. 
Department of Political Studies. (2005). Third world politics course handbook. University of Cape Town.

Downes, Stephen. (2005). E-learning 2.0. eLearn Magazine, 2005(10). Retrieved May 17, 2006, from $<$ http://www.elearnmag.org/subpage.cfm?section=articles\&article=29-1>.

Engestr" m, Yrj” . (1987). Learning by expanding: An activity-theoretical approach to developmental research. Helsinki: Orienta-Konsultit.

Engestr” m, Yrj”. (1990). Learning, working, and imagining. Helsinki: Orienta-Konsultit.

Engestr" m, Yrj” . (1999). Innovative learning in work teams: Analysing cycles of knowledge creation and practice. In Yrj“ Engestr“ m, Reijo Miettenen, \& Raija-Leena Punam“ ki (Eds.), Perspectives on activity theory (pp.377-404). Cambridge: Cambridge UP.

Engestr" m, Yrj”. (2001). Expansive learning at work: Toward an activity theoretical reconceptualization. Journal of Education and Work, 14(1), 133-156.

Feldman Barr, Terri, Dixon, Andrea L., \& Gassenheimer, Jule B. (2005). Exploring the "Lone Wolf" phenomenon in student teams. Journal of Marketing Education, 27(1), 81-90.

Garza, Susan, \& Hern, Tommy. (2005). Collaborative writing tools: Something wiki this way comes - or not? Kairos 10(1). Retrieved May 17, 2006, from <http://falcon.tamucc.edu/wiki/WikiArticle/Home>.

Giles, Jim. (2005). Internet encyclopaedias go head to head. Nature: International Weekly Journal of Science, 438, 900-901. Retrieved November 4, 2006, from <http://www.nature.com/nature/journal/v438/ n7070/full/438900a.html>.

Goodsell, Anne, Maher, Michelle, Tinto, Vincent, Smith, Barbara, \& McGregor, Jean. (1992). Collaborative learning: A sourcebook for higher education. National Center on Postsecondary Teaching, Learning, and Assessment. Retrieved November 5, 2006, from <http://eric.ed.gov/ERICWebPortal/contentdelivery/ servlet/ERICServlet?accno=ED357705>.

Guzdial, Mark, Jochen, Rick, \& Kehoe, Colleen. (2001). Beyond adoption to invention: Teacher-created collaborative activities in higher education. Journal of the Learning Sciences, 10(3). Retrieved May 17, 2006, from <http://coweb.cc.gatech.edu:8888/csl/uploads/24/CoWeb-final-Jan01.pdf>.

Huff, Lenard C., \& Jones, Wayne. (2002). The development and consequences of trust in student project groups. Journal of Marketing Education, 24(1), 24-34.

Jahreie, Cecilia F., \& Ludvigsen, Sten. (2005). Transformation of co-developing activity systems: Co-configuration and the formation of a collective object. ISCAR, Seville, 20-24 September.

Kuutti, Kari. (1996). Activity theory as a potential framework for human-computer interaction research. In B. Nardi (Ed.), Context and consciousness: Activity theory and human computer interaction (pp. 17-44). Cambridge: MIT Press.

Lave, Jean, \& Wenger, Etienne. (1991). Situated learning: Legitimate peripheral participation. Cambridge: Cambridge UP.

Laurillard, Diana. (2002). Rethinking university teaching: A framework for the effective use of learning technologies.

London: Routledge.

Lund, Andreas, \& Smørdal, Ole. (2006). Is there a space for the teacher in a Wiki? 2006 International Symposium on Wikis, August 21-23, Odense, Denmark.

Leont'ev, Alexei. (1978). Activity, consciousness, and personality. Englewood Cliffs: Prentice Hall.

Leont'ev, Alexei. (1981). Problems of the development of the mind. Moscow: Progress Publishers.

Lipponen, Lasse. (2002). Exploring foundations for computer-supported collaborative learning. In Gerry Stahl (Ed.), Computer support for collaborative learning: Foundations for a CSCL community (pp. 72-81). Proceedings of the Computer-supported Collaborative Learning 2002 Conference. Hillsdale, NJ: Erlbaum.

Lipponen, Lasse, Hakkarainen, Kai, \& Paavola, Sami. (2004). Practices and orientations of CSCL. In Jan Strijbos, Paul Kirschner, \& Rob Martens (Eds.), What we know about CSCL and implementing it in higher education (pp. 31-50). Boston: Klewer.

Miettinen, Miikka, Kurhila, Jaakko, Nokelainen, Petri, \& Tirri, Henry. (2005). OurWeb: Transparent groupware for online communities. Web Based Communities 2005, 23-25 February, Algarve, Portugal. Available: $<$ http://cosco.hiit.fi/edutech/publications/wbc2005.pdf $>$. 
O’Neill, Mellisa E. (2005). Automated use of a wiki for collaborative lecture notes. Technical Symposium on Computer Science Education archive. Proceedings of the 36th SIGCSE technical symposium on computer science education. St. Louis, Missouri, USA.

Palmquist, Mike. (2003). A brief history of computer support for writing centers and writing-across-the-curriculum programs. Computers and Composition, 20(4), 395-413.

Rasmussen, Ingvill, KrangeF Ingeborg, \& Ludvigsen, Sten. (2005). Understanding the task: How is agency distributed between tools, students and teachers in technology-rich learning environments? International Journal of Educational Research, 39, 839-849.

Rick, Jochen, \& Guzdial, Mark. (2006). Situating CoWeb: A scholarship of application. ljcscl, 1(1), 89-115.

Stahl, Gerry. (2001) WEBGUIDE: Guiding collaborative learning on the Web with perspectives. Journal of Interactive Media in Education, 1. Retrieved November 4, 2006, from <http://www-jime.open.ac.uk/2001/1>.

Veerman, Arja. (2000) Chapter 3: Software for problem solving through collaborative argumentation. Computersupported collaborative learning through argumentation. PhD Dissertation, University of Utrecht. Retrieved October 30, 2006, from <http://igitur-archive.library.uu.nl/dissertations/1908992/c3.pdf>.

Vygotsky, Lev. (1962). Thought and language. Cambridge: MIT Press.

Vygotsky, Lev. (1978). Mind in society: The development of higher psychological processes. Cambridge: Harvard UP.

Warschauer, Mark. (1999). Electronic literacies: Language, culture, and power in online education. Hillsdale, NJ: Lawrence Erlbaum Associates.

Wartofsky, Marx. (1979). Models: Representation in scientific understanding. Dordrecht: D. Reidel Publishing Co. Wells, Gordon. (1999). Dialogic inquiry: Toward a sociocultural practice and theory of education. Cambridge: Cambridge UP.

Wenger, Etienne, McDermott, Richard, \& Snyder, William. (2002). Cultivating communities of practice: A guide to managing knowledge. Harvard: Harvard Business School Press.

Wertsch, James. (1991). Voices of the mind. A sociocultural approach to mediated action. Cambridge: Harvard UP. 